J. Amer. Soc. Hort. Sci. 116(4):680-683. 1991.

\title{
Changes in Xylem Constituents in Response to Rest-breaking Agents Applied to Apple before Budbreak
}

\author{
J.G.M. Cutting ${ }^{1}$, D.K. Strydom, and G. Jacobs \\ Department of Horticultural Science, University of Stellenbosch, Stellenbosch 7600, South Africa
}

D.U. Bellstedt and K.J. Van Der Merwe

Department of Biochemistry, University of Stellenbosch, Stellenbosch 7600, South Africa

E.W. Weiler

Lehrstuhl für Pflanzenphysiologie, Ruhr Universität, D-4630 Bochum, West Germany

Additional index words. dormancy, Malus domestica, cytokinins, minerals, sorbitol

Abstract. Xylem sap was vacuum-extracted weekly from 1-year-old apple shoots from trees treated with dinitro-ocresol (DNOC) oil, hydrogen cyanamide, or untreated controls. Sampling began 1 week before treatment and continued until 2 weeks after budbreak had occurred in the control trees. Sorbitol, calcium, magnesium, potassium, and zeatin-type cytokinin concentrations were determined by enzymatic, atomic absorption, and immunoassay methods, respectively. The rest-breaking treatments resulted in earlier and more intense budbreak. Xylem sap cytokinin concentrations increased rapidly in response to the rest-breaking chemicals and peaked just before or at budbreak. The rapid increase in cytokinin was closely followed by increases in calcium and magnesium concentrations in the sap. Potassium concentration appeared to be unaffected by rest-breaking treatment. Sorbitol levels dropped rapidly as a result of the rest-breaking treatments and appeared to be used rapidly in budbreak and early bud growth.

The inability of apple trees with a high chill requirement to break rest in areas characterized by warm winters is well documented (Erez, 1987). The major problem resulting under such conditions is delayed foliation. Rest can be broken under certain conditions by using chemicals such as DNOC oil (Samish, 1945) or cyanamide (Shulman et al., 1983). However, little is known about the mode of action and the effect on tree physiology of these rest-breaking agents, except that just sublethal dosages of the chemicals are usually required to obtain the desired response (Erez, 1987) and that DNOC oil combinations reduce oxygen uptake. Taylorson and Hendricks (1977) have shown that many of the rest-breaking chemicals inhibit catalase and allow activation of certain peroxidases.

Budbreak is thought to be regulated internally by plant growth substances (PGSs), particularly gibberellins (Donoho and Walker, 1957) and root-produced cytokinins (Jones, 1973; Torrey, 1976). The role of growth regulators in dormancy has been recently reviewed (Lavender and Silim, 1987), although the possibility of a direct role by cytokinins has been questioned (Belding and Young, 1989; Young 1989). Understanding the physiology of rest breakage could result in the use of less expensive and safer chemicals. An investigation into the effect of rest-breaking agents applied during late winter upon xylem sap constituents of 'Granny Smith' apple trees before and shortly after budbreak is reported.

\section{Materials and Methods}

Bearing 'Granny Smith' apple trees were sprayed on 2 Sept. 1987 with either $4 \%$ cyanamide or $4 \%$ DNOC oil. Unsprayed

Received for publication 28 June 1990. J. G. M. C., D. K. S., and G.J. thank the Molteno Brothers Trust Fund, The Foundation for Research Development, and The Lombardi Trust Fund for generous financial support. We thank Marlene Lambrechts, George Honeybome, Willem van Kervel, and Pia Nel for excellent technical assistance. The cost of publishing this paper was defrayed in part by the payment of page charges. Under postal regulations, this paper therefore must be hereby marked advertisement solely to indicate this fact.

'Present address: Dept. of Horticultural Science, Univ. of Natal, P.O. Box 375, Pietermaritzburg 3200, South Africa. trees served as a control. At the time the trees were sprayed, they had received 383 Richardson chill units. Treatments were replicated 10 times using three trees per plot in a completely randomized block design.

One-year-old shoots, $\approx 1 \mathrm{~m}$ long, were collected from the trees before sunrise (air temperatures ranged from 4 to $10 \mathrm{C}$, depending on the date). Shoots were collected on 25 Aug. (1 week before the spray application) and weekly thereafter until 27 Oct. Xylem sap was also extracted on 24 Nov. and 2 Dec. from sprouted and nonsprouted shoots on control trees. Xylem sap was extracted from the shoots using a method similar to that described by Belding and Young (1989). The xylem sap extracted from five shoots per treatment was pooled; this was repeated for each of the 10 replicates. After extraction, the xylem sap was rapidly frozen and stored at $-20 \mathrm{C}$ until analysis.

Zeatin-type cytokinin (calculated as zeatin riboside equivalents) concentrations in the xylem sap were determined directly by enzyme-linked immunosorbent assay (ELISA) (Eberle et al., 1986), without any sample purification, using $0.1 \mathrm{ml}$ suitably diluted sap in Tris buffer. A minor modification to the ELISA procedure was the substitution of chicken antimouse for rabbit antimouse serum. The zeatin riboside values obtained were validated by dilution analysis of xylem sap samples to which known amounts of zeatin riboside were added.

The tentative identification of the cytokinin compliment in the xylem sap in response to cyanamide was achieved using high-performance liquid chromatography (HPLC) immunohistograms. The following conditions were used for the HPLC separations in this study: Aliquots $(1 \mathrm{ml})$ of pooled xylem sap samples taken 1 week before budbreak, from either cyanamide or control trees, were filtered through a $0.45-\mu \mathrm{m}$ disposable filter and injected into the HPLC. Separations were achieved on a Waters (Milford, Mass.) gradient HPLC fitted with a U6K variable volume injector and a $10 \times 250-\mathrm{mm}$ Zorbax, 5- $\mu \mathrm{m}$

Abbreviations: ELISA, enzyme-linked immunosorbent assay; DNOC, dinitroo-cresol; HPLC, high-performance liquid chromatography; RIA, radioimmunoassay. 
semiprep ODS column (DuPont, Wilmington, Del.). Retention times of zeatin, zeatin riboside, dihydrozeatin, dihydrozeatin riboside, isopentenyl adenine, and isopentenyl adenosine were determined using authentic standards. The column was eluted with a gradient of $10 \%$ methanol in $0.1 \mathrm{~N}$ acetic acid buffered to $\mathrm{pH} 3.5$ with triethylamine to $50 \%$ methanol over $70 \mathrm{~min}$ at a flow rate of $1 \mathrm{ml} \cdot \mathrm{min}^{-1}$ One-minute fractions were collected, reduced to dryness in a Savant (Farmingdale, N. Y.) concentrator, then redissolved in $2 \mathrm{ml}$ methanol, and subjected to radioimmunoassay for zeatin, dihydrozeatin, and isopentenyl-type cytokinins (Cutting et al., 1983; Hofman et al., 1986). Raw data were analyzed using an on-line computer and the Securia data reduction radioimmunoassay package (Packard Instrument Co., Downers Grove, Ill., 1986 publication no. 169-3016).

Calcium, magnesium, and potassium concentrations in the sap were determined using atomic absorption and flame emission analytical methods. Xylem sap samples were centrifuged at $3000 \times \mathrm{g}$ for $10 \mathrm{~min}$ and the supernatant suitably diluted before determination. Sorbitol was determined calorimetrically in an assay based on sorbitol dehydrogenase (Boehringer Mannheim kit no. 724 831) using a Technicon autoanalyser (Technicon Instruments Corp., Tarrytown, N.Y. 1976 publication no. UA40170-01).

\section{Results}

The use of hydrogen cyanamide and DNOC oil treatments resulted in a 3- and 4-week earlier budbreak (budbreak was 50\% of full bloom) over the control in 'Granny Smith' apple, respectively. Budbreak in the control showed typical delayed foliation symptoms, such as prolonged and reduced budbreak.

In control trees, zeatin-type cytokinins in the xylem sap rose steadily during the 6 weeks before budbreak from $<1 \mathrm{ng} \cdot \mathrm{m}^{-1}$ to $\approx 5 \mathrm{ng} \cdot \mathrm{m}^{-1}$. This was followed by a rapid increase to between 12 and $17 \mathrm{ng} \cdot \mathrm{ml}^{-1}$ (depending upon treatment) immediately before and/or at budbreak. Both DNOC oil and cyanamide treatment resulted in a rapid increase in the concentration of zeatin-type cytokinin in the xylem sap within 2 weeks of application (Fig. la).

The possible presence of interfering contaminants in the ELISA for zeatin-type cytokinins was determined using dilution analysis curves and checking for parallelism against a standard curve (Pengelly, 1985). A typical set of quality control curves are presented in Fig. 2. The sap dilution curve paralleled the standard curve, indicating an absence of immunoassay-interfering compounds. HPLC immunohistograms of the cytokinin compliment showed that one compound with chromatographic and immunological properties similar to zeatin riboside was present in measurable quantities (Fig. 3) and is referred to as zeatin riboside.

Calcium and magnesium concentrations in xylem sap showed similar patterns for all treatments in that these ions increased by a factor of between 3 and 5 during and/or immediately after budbreak (Fig. $1 \mathrm{~b}$ and c). In addition, both DNOC oil and cyanamide resulted in a 3- to 4-week earlier increase in both calcium and magnesium in the xylem sap. Potassium xylem sap concentrations only began to rise $\approx 2$ to 3 weeks after budbreak and appeared to be unaffected by the treatments (Fig. 1d). Sorbitol sap concentrations were $\approx 800 \mu \mathrm{g} \cdot \mathrm{ml}^{-1}$ when sampling began and declined before and shortly after budbreak to 100 $\mu \mathrm{g} \cdot \mathrm{ml}^{-1}$ in the DNOC and cyanamide treatments and to 400 $\mu \mathrm{g} \cdot \mathrm{ml}^{-1}$ in the control. Sorbitol concentrations then increased to $\approx 1000 \mu \mathrm{g} \cdot \mathrm{ml}^{-1}$ in the DNOC oil and cyanamide treatments and to $\approx 600 \mu \mathrm{g} \cdot \mathrm{ml}^{-1}$ in the control (Fig. 1e).

\section{Discussion}

The release of dormancy is important in warm winter regions where prolonged dormancy due to insufficient cold is an important obstacle to economic production of temperate crops. Both DNOC oil and hydrogen cyanamide treatments appear to cause disruption of metabolism, leading to growth. We, therefore, have a strong, repeatable, and reliable field contrast to investigate as a tool toward understanding the release of deciduous trees from winter dormancy. While these rest-breaking compounds are undoubtedly the trigger, it would be of great benefit to determine how these compounds activate the endogenous release mechanism. Saure (1985) believes most researchers in this field regard this endogenous control to occur via one or more of the plant growth regulators. If this is the case, the endogenous growth regulator(s) should show a similar pattern in response to dormancy-releasing treatments, and this should precede the normal consequences of bud release, such as rises in the sap concentration of certain minerals and a decline in xylary carbohydrate reserve concentrations.

In this study, xylary potassium concentrations did not appear to be greatly affected by the rest-breaking chemicals. Most of the tree reserve potassium is stored in the roots (Terblanche, 1972), and an increase in the xylem sap would, therefore, depend on increased root activity. Our results, therefore, tentatively indicate that the rest-breaking chemicals have little or no effect on root activity. In contrast, both calcium and magnesium xylary concentrations increased rapidly in response to chemical rest-breaking treatment, reaching a maximum at or shortly after budbreak. A large proportion $(60 \%$ to $70 \%)$ of these two minerals are stored in the bark and in 1-year-old apple wood (Terblanche, 1972); calcium, in particular, is bound by extracellular cell wall moieties and the plasma membrane (Poovaiah, 1988). Optimal chemically induced budbreak is obtained when the concentration of the rest-breaking agents used is near the lethal limit (Erez, 1987). At these concentration levels, most rest-breaking agents promote the activation of certain peroxidases (Taylorson and Hendricks, 1977). The rapid increase in the calcium and magnesium in response to rest-breaking treatments is most likely due to extracellular releases from damaged or impaired membrane proteins before the resumption of root activity.

Sorbitol is the primary photosynthetic product in many species of the Rosaceae, including Malus, and accounts for up to $90 \%$ of the carbon exported from the leaf (Loescher, 1987). Sorbitol has been found to be a major carbohydrate in apple xylary sap and shows a seasonal increase with chilling and the fulfillment of the dormancy requirement (Williams and Raese, 1974). These authors concluded that sorbitol is an important reserve of storage carbohydrate in resting apple trees. In our study, sorbitol xylary concentrations started to decline within 2 weeks of the application of the rest-breaking treatment and reached a minimum 1 to 2 weeks after budbreak. The decline was most marked in the hydrogen cyanamide treatment, which resulted in earlier budbreak. In the untreated control, the xylary sorbitol concentrations declined more slowly and never to as low a level as for the chemical rest-breaking treatments. The controls suffered from delayed foliation, with much fewer buds sprouted, which may have placed a lower demand on carbohydrate reserves.

It has previously been shown that the primary cytokinin in the xylem sap of apples is zeatin or zeatin riboside (Jones, 1973). Our study, using more recent technology of combined HPLC separation and immunoassay quantitation, confirmed these results and showed that only one major compound with chro- 

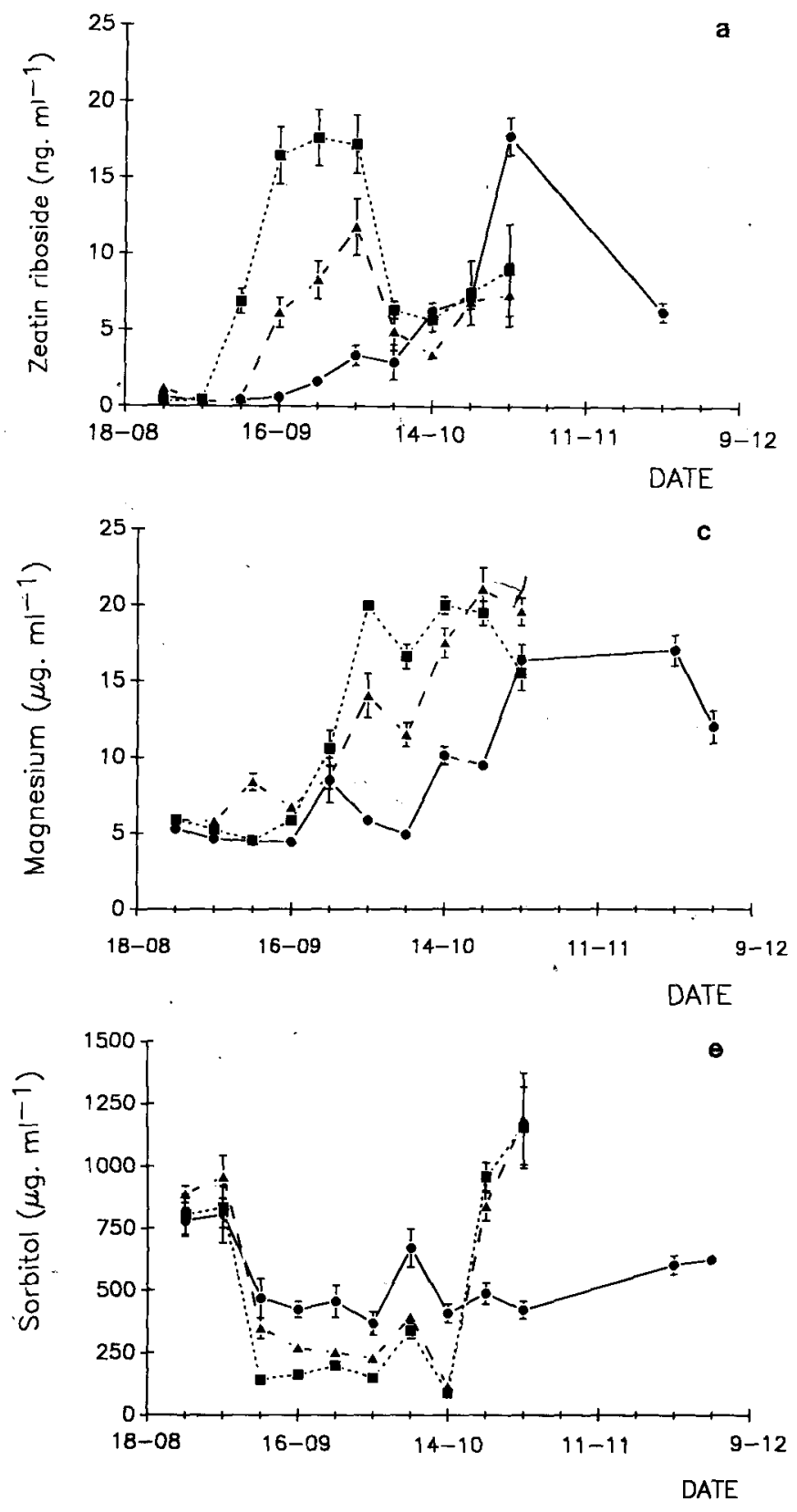

matographic and immunological properties similar to authentic zeatin riboside occurred in apple sap. While this method does not positively identify the compound as GC-MS would, we believe it is safe to assume that the compound present in the sap is indeed zeatin riboside. Small amounts of isopentenyl-type cytokinins were also detected; however, the levels were so low that this PGS was not investigated further. Because of the sensitivity of immunoassay, no purification of the xylem sap to concentrate cytokinins was necessary, negating the necessity for the determination of recoveries.

Our study found that zeatin riboside increased in response to the two rest-breaking treatments and reached a concentration maximum 1 week before budbreak. Young (1989) believes that chilling is not responsible for the increase in xylary cytokinin before budbreak. However, it must be remembered that the pruning treatments used by Young were highly stimulator and the trees were single stems in pots. Our results with intact, older, grafted, and more complex trees reacted very similarly
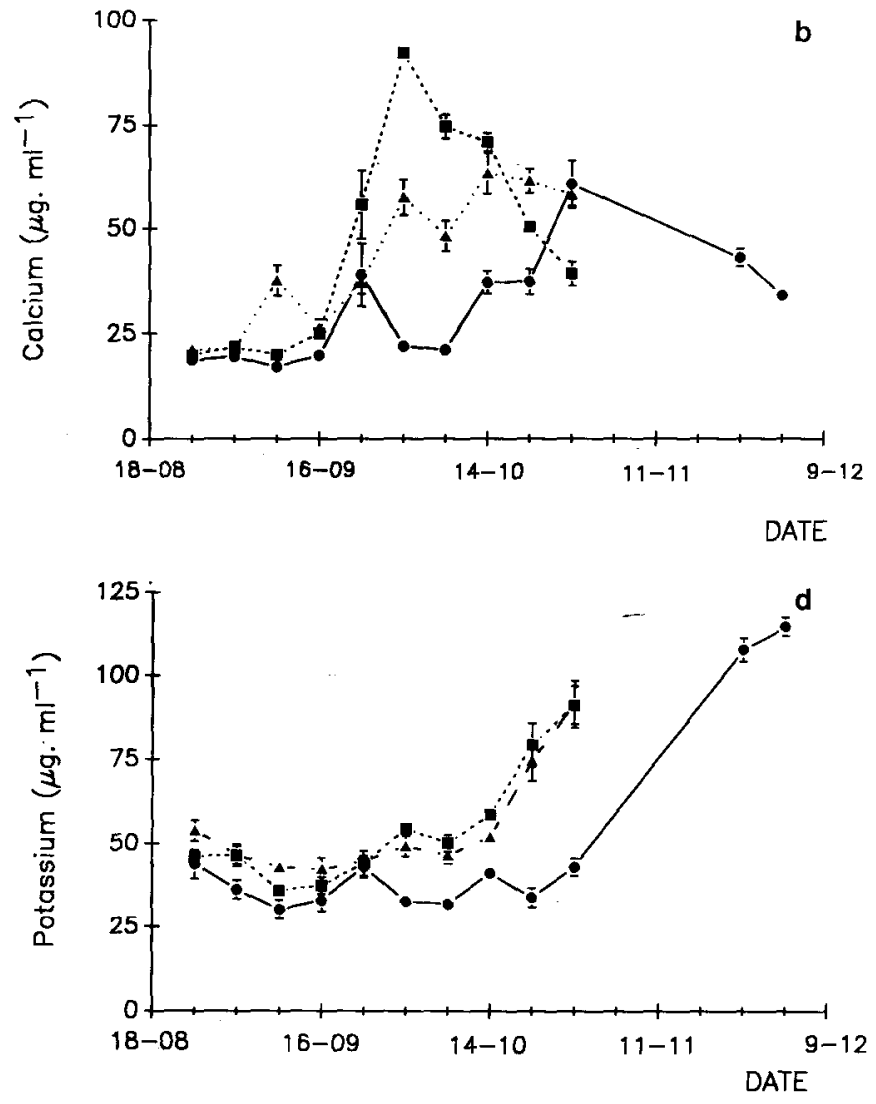

Fig. 1. Zeatin riboside (a), calcium (b), magnesium (c), potassium (d), and sorbitol (e) concentrations in apple xylem sap after trees had been treated with $4 \%$ DNOC oild-A)or $4 \%$ hydrogen cyanamide( $\mathbf{\square}--\mathbf{D})$ on 2 Sept. or left untreated (control(0-) Time of budbreak (50\% of full bloom) was 30 Sept. for hydrogen cyanamide, 6 Oct. for DNOC oil, and 27 Oct. for the control. Data are presented as means \pm SE.

(if rest-breaking chemicals are viewed as highly stimulator). With rest-breaking chemicals, and particularly hydrogen cyanamide, we were able to shift the time of the cytokinin increase up to 5 weeks earlier and change the rate of the increase relative to the control. In both cases, this increase in xylem sap cytokinin concentration occurred just before budbreak. The untreated control, which received insufficient chilling, showed a much slower increase in xylem sap cytokinin concentration. The higher concentration of zeatin riboside in xylary sap just before budbreak could be due to various causes. These include increased export from roots, reduced localized utilization, localized synthesis, or release from bound/storage forms. We do not believe that the first two possibilities have merit, considering the rapid cytokinin increase, the physiological state of the tree, the low root temperatures during that time of the year, and the low concentrations of zeatin riboside present in the control at that time. This argument agrees with the postulations of Tromp and Ovaa (1990) that the increase in apple xylary cytokinins in spring is from 

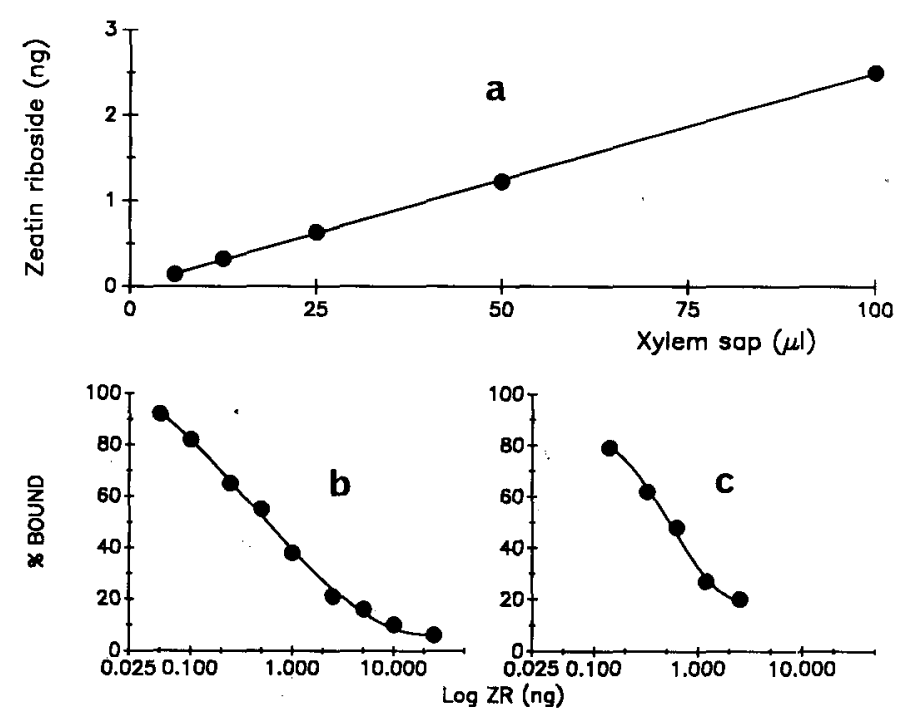

Fig. 2. Determination of possible nonspecific interference in the ELISA for zeatin riboside (ZR) using crude serially diluted xylem sap (a), and checking for parallelism against the standard dose response curve (b) using the serially diluted xylem sap (c).

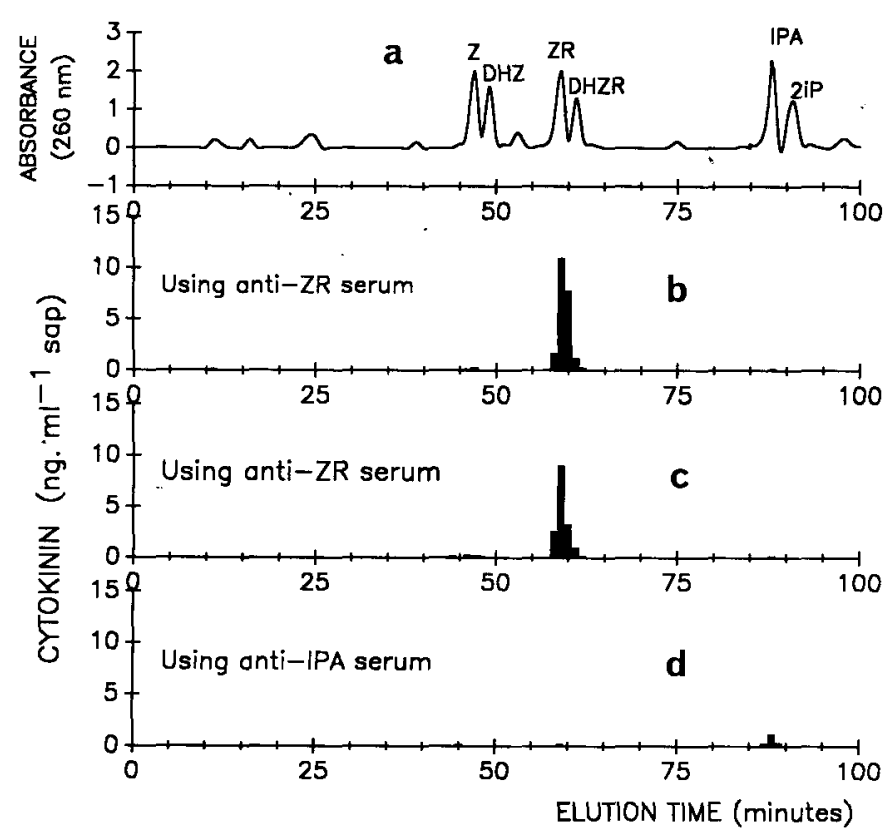

Fig. 3. HPLC immunohistograms of apple xylem sap 1 week before budbreak from hydrogen cyanamide-treated (b and d) and untreated control trees (c). The UV trace of authentic cytokinin standards shows retention times as they eluted off the HPLC column (a).

either storage forms or de novo synthesis. In other tree species, such as Populus and Salix, the major storage cytokinin is zeatin glucoside and the major xylary cytokinin is zeatin riboside (Hewett and Wareing, 1974). The antibody used in our study does not bind with zeatin glucoside, but, considering that zeatin riboside is the major apple xylary sap cytokirrin, as found by Jones (1973) and by us, we feel it safe to believe that storage cytokinins would be present, possibly zeatin glucoside. The slow increase in cytokinins in the xylem sap of the control is more likely due to current-season root production and shows a similar rate of increase to potassium (which is dependent on root activity). This pattern is in stark contrast to the rest-breaking treatments. This study has shown that xylary cytokinin concentrations rise dramatically before budbreak in response to chemical rest-breaking treatment in the absence of sufficient cold and confirms earlier findings that low temperatures and the increase in xylary cytokinins are not related (Young, 1989). Further research needs to be done to determine whether the origin of the xylary cytokinins is from localized synthesis or release from storage.

\section{Literature Cited}

Belding, R.D. and E. Young. 1989. Shoot and root temperature effects on xylary cytokinin levels during budbreak in apple trees. HortScience 24:115-117.

Cutting, J.G.M., A.W. Lishmean, A. van der Hoven, B.N. Wolstenholme. 1983. Development of a radioimmunoassay for the cytokinin isopentenyl adenosine. Crop Production 12:133-135.

Donoho, C. W. and D.R. Walker. 1957. Effect of gibberellic acid on breaking of rest in Alberta peaches. Science 126:1178-1179.

Eberle, J., A. Arnscheidt, D. Klix, and E.W. Weiler. 1986. Monoclonal antibodies to plant growth regulators. III Zeatin and dihydrozeatin riboside. Plant Physiol. 81:516-521.

Erez, A. 1987. Chemical control of budbreak. HortScience 22:12401243.

Hewett, E.W. and P.F. Wareing. 1974. Cytokinin changes during chilling and bud burst in woody plants, p. 693-701. In: R.L. Bileski, A.R. Ferguson, and M.M. Cresswell (eds.). Mechanism of regulation of plant growth. Royal Soc. New Zealand, Wellington.

Hofman, P.J., B.C. Featonby-Smith, and J. van Staden. 1986. The development of ELISA and RIA for cytokinin estimation and their application to a study of lunar periodicity in Ecklonia maxima (Osbeck) Papenf. J. Plant Physiol. 122:455-466.

Jones, O.P. 1973. Effects of cytokinins in xylem sap from apple trees on apple shoot growth. J. Hort. Sci. 48:181-188.

Lavender, D.P. and S.N. Silim, 1987. The role of plant growth regulators in dormancy in forest trees. Plant Growth Regulat. 6:171191.

Loescher, W.H. 1987. Physiology and metabolism of sugar alcohols in higher plants. Physiol. Plant. 70:553-557.

Pengelly, W.L. 1985. Validation of immunoassay, p. 35-43. In: M. Bopp (ed.). Plant growth substances. Springer-Verlag, Berlin.

Poovaiah, B. W. 1988. Molecular and cellular aspects of calcium action in plants. HortScience 23:267-271.

Samish, R.M. 1945. The use of dinitro cresol mineral oil sprays for the control of prolonged rest in apple orchards. J. Pomol. Hort. Sci. 21:164-179.

Saure, M.C. 1985. Dormancy release in deciduous fruit trees. Hort. Rev. 7:239-300.

Shulman, Y., G. Nir, L. Fauberstein. and S. Lavee. 1983. The effect of cyanamide on the release from dormancy of grapevine buds. Scientia Hort. 19:97-104.

Taylorson, R.B. and S.B. Hendricks. 1977. Dormancy in seeds. Annu. Rev. Plant Physiol. 28:331-354.

Terblanche, J.H. 1972. Seisoensopname en verspreiding van tien voedingselemente by jong applebome gekweek in sandkulture (Seasonal uptake and distribution of ten nutritional elements by young apple trees grown in sand culture). PhD Diss., Univ. of Stellenbosch, Stellenbosch, South Africa.

Torrey, J.G. 1976. Root hormones and plant growth. Annu. Rev. Plant Physiol. 27:435-459.

Tromp, J and J.C. Ovaa. 1990. Seasonal changes in the cytokinin composition of xylem sap of apple. J. Plant Physiol. 136:606-610.

Williams, M.W. and J.T. Raese. 1974. Sorbitol in tracheal sap of apple as related to temperature. Physiol. Plant. 30:49-52.

Young, E. 1989. Cytokinin and soluble carbohydrate concentrations in xylem sap of apple during dormancy and budbreak. J. Amer. Soc. Hort. Sci. 114:297-300. 